\title{
Means-tested public support and the interaction between long-term care insurance and informal care
}

\author{
Jean-Marc Bascans \\ CRIEF-IRIAF, University of Poitiers, Poitiers, France
}

Christophe Courbage

Haute Ecole de Gestion de Genève, University of Applied Sciences Western Switzerland (HES-SO)

Cornel Oros

CRIEF-IRIAF, University of Poitiers, Poitiers, France

LEO, University of Orléans, Orléans, France

\begin{abstract}
This paper investigates theoretically how the structure of means-tested public longterm care (LTC) support influences the relationship between LTC insurance and informal care. Three types of public support encountered in various means-tested LTC schemes are examined. First, the level to be considered for means-testing only takes into account the level of wealth of the recipient without considering the cost of LTC or the possible insurance benefits. Second, the public support also considers the LTC needs of the recipient. Third, the means-test structure takes into consideration insurance benefits as well. Our results show that the optimal levels of insurance and informal care as well as their relationship are strongly influenced by the ways means-tested public support for LTC is structured, which have important implications in terms of public policy for the financing of LTC needs.
\end{abstract}

Keywords: long-term care, informal care, long-term care insurance, means testing

JEL: D1, H2, I1, J1 


\section{Introduction}

The ageing of population, combined with declining fertility rates and increasing severe disabilities among elderly people (Lafortune et al., 2007), expand the needs for long-term care (LTC) coverage and require increasing resources to finance LTC costs. Many countries are under pressure to find solutions to finance LTC and have put this item at the top of their economic and social agenda. Apart from their own resources, individuals can rely on three main sources for financing LTC costs: the government, the family, and private insurers. So far, no unitary and consensual approach has been achieved as the best way to share responsibilities and actions among these three actors in order to allow sustainable funding of LTC risks (Costa-Font and Courbage, 2012). As a consequence, a great diversity exists among the sources financing LTC risk in Europe and elsewhere (Colombo et al., 2011).

LTC costs are mainly (and partially) financed by public expenditures, which represented on average about $1.2 \%$ of GDP within a group of 25 countries from OECD in 2008 (Colombo et al., 2011). However, discrepancies among these countries are very important as a result of different needs, different organization of the public services, and different levels of social benefits. These public schemes are typically means-tested in that wealthy recipients are made to pay more towards their cost of LTC expenditures. The way mean-tested is defined is also heterogeneous amongst countries (Colombo et al., 2011). The level to be considered for meanstesting could only take into account the level of wealth of the recipient without considering the cost of LTC or the possible insurance benefits as it happens in The Netherlands or Hungary. It could also consider the LTC needs of the recipient and then integrate the level of LTC expenditures in the level of wealth to mean-test public support as in France or Finland. The means-test structure could also include insurance benefits as is the case in various states of the U.S. or in New-Zealand. It also happens that the stringency of public support to wealth varies from one country to the other.

The family plays also an important role in LTC funding. In all European countries, the transfers between generations in terms of time and money are significant; with almost three people aged 50 or more out of ten providing financial support and more than four out of ten providing time help (Laferrère and Wolff, 2006). This kind of informal help is based on family relations, on the capacity and willingness of the helping persons to provide support. Several factors can influence the amount and the organization of the informal help, such as family disintegration, geographical remoteness, women's work, fertility rates, the amount of inheritance, and the availability of LTC public support as well as private insurance benefits 
(Van Houtven and Norton, 2008). It is also generally admitted that supporting a dependent relative has a cost in money and time, as well as an impact on the professional and personal life and the health of the helping person (Coe and Van Houtven, 2009)

Finally, LTC insurance markets play a role in various countries but at lower level, with the exception of France and the United States which represent the two most important markets for voluntary LTC insurance. In 2010, about $15 \%$ of the French population aged 40 and over and $10 \%$ of the U.S. population aged 60 and over had insurance (SCOR, 2012). The size of the market seems relatively small in comparison to the very substantial level of private expenditures involved. This lack of LTC insurance development can be accounted for by the specificities of supply and demand factors, including the issue of long risks insurability, asymmetric information, LTC risk pricing, bias in risk perception, and limited and myopic knowledge ${ }^{1}$. In particular, public support and the availability of informal care have been shown to crowd out the optimal purchase of LTC insurance (Pauly, 1990; Brown and Finkelstein, 2008).

In this work, we advocate that the structure of means-tested public support has a strong influence on how the sources of funding interact with each other and, in particular, on the link between informal care and insurance. The interaction between insurance and informal care is an important issue, as LTC insurance is suspected of inducing moral hazard effects on the part of potential caregivers already by Pauly (1990) and Zweifel and Strüwe (1996, 1998) because it encourages children as potential caregivers to substitute formal care for their efforts. This could therefore deter the parent from purchasing insurance and explain the sluggish development of LTC insurance. If a few studies have provided a theoretical analysis of the agents' behavior in the family structure under the circumstances of LTC financing (Zweifel and Strüwe, 1996, 1998; Pestieau and Sato, 2008; Courbage and Zweifel, 2011; Courbage and Eeckhoudt, 2012), none has dealt with the impact means-tested public support structure may have on the strategic interactions between parent and child.

This paper aims to fill this gap by developing a theoretical model to examine the impact of different types of means-tested public support on the nature of the interactions between parents and children and therefore, on the use of private insurance or of informal care as instruments for LTC financing. To that aim, we consider three scenarios that are possibly encountered in various means-tested LTC schemes and which could influence the relationship between the purchase of LTC insurance by elderly parents and the supply of informal care by adult children

\footnotetext{
${ }^{1}$ For a comprehensive review of the factors explaining the limited development of LTC insurance markets, we refer the readers to Brown and Finkelstein (2009).
} 
to their elderly parents. First, the level to be considered for means-testing only takes into account the level of wealth of the recipient without considering the cost of LTC or the possible insurance benefits. Second, the public support considers the LTC needs of the recipient and then integrates the level of LTC expenditures in the level of wealth to means-test public support. Third, the means-test structure includes insurance benefits.

We also investigate how exogenous shocks modify the interactions between the decision to purchase insurance and the decision to provide informal care. We consider exogenous shocks that are likely to have an influence on both the demand for LTC insurance and the offer of informal care. These shocks can either be under the control of governments with a direct impact on public budgets such as a variation in the tax rate on inheritance, the level of public support as well as its stringency. Other shocks are beyond government control and include the wealth levels of both individuals, the cost of formal care, the opportunity cost of informal care and the price of insurance.

Our results depend on the level of child altruism, i.e. whether the child is solely interested in the bequest or if she/he also derives satisfaction from caregiving. In the former situation, we find that, in the case where means-tested public support depends only on initial wealth, optimal insurance depends negatively on informal care. Yet, when LTC expenditures are included in the level of wealth to be means-tested, then both informal care and insurance depends on the sensitivity of public support to wealth as well as their relationship, possibly leading to complementarity between the two. Finally, when insurance is included in the wealth level to means-test, both the optimal levels of insurance and of informal care can be nil in the case of very stringent public support. In the case where children also derive satisfaction from caregiving, the optimal level of informal care depends positively on insurance when the level of wealth to be means-tested includes either only initial wealth or LTC expenditures, while the optimal level of insurance is not modified.

These results show that the ways means-tested public support for LTC is structured strongly influence the optimal levels of insurance and informal care as well as their relationships. These results can be highly relevant in terms of public policy for the financing of LTC needs, in particular in the aim of influencing both the purchase of insurance and the supply of informal care.

The paper is organised as follow. In the next section, we introduce the benchmark model and the hypothesis used. In Section 3, we present the joint optimal conditions on insurance and informal care, i.e. the reaction functions, according to the different configurations of means- 
tested public support. Section 4 addresses the results of comparative statics. Finally, a short conclusion is provided in the last section.

\section{The model}

Based on Courbage and Zweifel (2011) and Courbage and Eeckhoudt (2012) framework, we consider a parent and a child characterized by state-dependent VNM utility functions defined over wealth. The individual's utility functions are increasing and concave describing a riskaverse behavior. According to whether the parent is dependent or not, her/his utility functions are respectively $u($.$) or v($.$) with u()<.v($.$) for the same level of wealth. The child's utility$ functions are respectively $\bar{u}($.$) or \bar{v}($.$) according to the parent being dependent or not. We$ consider that the child is altruistic to the extent that she/he derives more utility from a given amount of wealth if the parent is not dependent, i.e. $\bar{u}()<.\bar{v}($.$) .$

Let $p$ be the probability of being dependent and needing LTC at home. Let $N$ be the quantity of formal LTC and $\beta$ the price of formal care per unity of care. The parent can purchase a LTC insurance policy which offers an indemnity $I$ in case of dependency. Let $\mu I$ be the insurance premium where $\mu$ is the premium per unity of coverage. If $\mu=p$, the premium is actuarially fair. If $\mu>p$, the premium is loaded.

The parent can also receive informal care, $e$, from his child. Informal care has the benefit of reducing the cost of LTC at a decreasing rate ${ }^{2}$. Hence $N$ depends on the level of informal LTC $e$ provided by the child and $N(e)$ is such that $N^{\prime}(e)<0$ and $N^{\prime \prime}(e)>0$. This means that we assume informal LTC and formal LTC to be substitutes ${ }^{3}$, i.e. more informal care leads to less formal care. This also means that we only consider LTC provided at home, both formally and informally.

We consider that the child values her/his effort with an opportunity $\operatorname{cost} \theta$ per unit of time. It could correspond to the wage if the caregiver is employed or to the level of pain of providing care. The child can expect an inheritance amounting to the share $s$ of the parent's final wealth ${ }^{4}$ (inversely proportional of the inheritance tax). In case the parent does not need LTC, the bequest

\footnotetext{
${ }^{2}$ We implicitly assume that elderly parents in need of assistance would first turn to informal care services and then formal care would adapt accordingly. However, we do not take into account any difference in quality between formal and informal LTC in our model.

${ }^{3}$ This relation finds strong support empirically (see e.g. Van Houtven and Norton, 2004; Bolin et al., 2007; Bonsang, 2009; Vilaplana Prieto and Jiménez-Martín, 2015).

${ }^{4}$ In the case of multiple siblings, it seems realistic to assume that the parent allocates, as far as he or she can, the bequest to the child who provides care.
} 
is larger because there is no cost of LTC to be paid. Let $z_{0}$ denote exogenous initial, pre-bequest wealth of the child.

We also consider two configurations of child altruism. We first consider the case of passive altruism under which the child is only interested in the final wealth of her/his parent which is bequeathed to the child. The second configuration corresponds to active altruism under which the child also derives satisfaction from providing informal care to her/his dependent parent.

Since the parent is supposed to be retired, there is no labour income that could contribute to wealth. The parent is thought to be rich enough to leave a bequest but poor enough to rely on some means-tested public support $b$ conditioned by the wealth of the parent $w$. We consider that the public support $b$ is a decreasing and concave function of wealth $w$, i.e. $b_{w}^{\prime}<0$ and $b_{w}^{\prime \prime}<0$. The level of public support also depends on the parameters $x$ and $y$ such that $b(w, x, y)$ where $x$ represents an exogenous parameter to reflect any increase in the level of public support $\left(\frac{\partial b}{\partial x}=b_{x}^{\prime}>0\right)$, and $y$ represents an increased stringency of public support $\left(\frac{\partial b_{w}^{\prime}}{\partial y}=b_{w y}^{\prime \prime}>0\right)$, i.e. the intensity of the sensitivity of public support to wealth.

According to the component of the wealth which is taken into consideration by the public authority in order to provide its financial support, three cases can be identified and successively developed in our approach. Firstly, public support depends only on the parent's initial wealth $w_{0}$, i.e. it writes as $b\left(w_{0}, x, y\right)$. Secondly, the level of wealth that is used to means-test also takes into consideration expenditures in formal LTC, i.e. such that $b\left(w_{0}-\beta N(e), x, y\right)$. Thirdly, the level of public support includes the amount of the insurance coverage, i.e. $b\left(w_{0}-\beta N(e)+I(1-\mu), x, y\right)$.

Our study makes the difference between these three configurations in order to analyze the impact of the structure of means-tested public support on the relationship between LTC insurance and informal care. We consider a non-cooperative game between the parent and the child and we identify the joint optimal behaviours of the two agents according to the different types of means-tested public support. While the decision of the parent to purchase insurance is made before the occurrence of the LTC risk, the decision of the child to provide informal care is made after the occurrence of the LTC risk. We make the assumption that the parent anticipates perfectly the reaction of the child to her/his insurance decision as this is usually done in the literature (see e.g. Pestieau and Sato, 2008). 


\section{Joint optimal behaviours of the parent and the child}

The joint optimal behaviours of the parent and the child are identified according to the two configurations of child altruism, i.e. passive and active altruism.

\subsection{Passive altruism}

\subsubsection{Public support conditioned only by the parent's initial wealth}

In this first case, the wealth considered for means-testing takes into consideration only the level of wealth of the recipient without considering the cost of LTC or the possible insurance benefits as it happens for instance in The Netherlands or Hungary. The expected utility functions of respectively the parent and the child are given by:

$V=p u\left(w_{0}+b\left(w_{0}, x, y\right)-\beta N(e)+(1-\mu) I\right)+(1-p) v\left(w_{0}-\mu I\right)$

$\bar{V}=p \bar{u}\left[z_{0}+s\left(w_{0}+b\left(w_{0}, x, y\right)-\beta N(e)+(1-\mu) I\right)-\theta e\right]+(1-p) \bar{v}\left(z_{0}+s\left(w_{0}-\mu I\right)\right)$

The two agents maximize their expected utility functions. For the parent, the first order condition (FOC) is:

$V_{I}=\frac{\delta V}{\delta I}=p(1-\mu) u^{\prime}(A)-\mu(1-p) v^{\prime}(B)=0$

with $A=w_{0}+b\left(w_{0}, x, y\right)-\beta N(e)+(1-\mu) I$ and $B=w_{0}-\mu I$

If the premium is actuarially fair, we can provide an explicit solution for the optimal level of insurance $I^{*}$. Indeed, in that case the FOC becomes:

$V_{I}=p(1-p)\left(u^{\prime}(A)-v^{\prime}(B)\right)=0$

The optimal level of insurance ${ }^{5}$ will then depend on the comparison between the wealth levels $A$ and $B$. We can thus have two cases satisfying the $\mathrm{FOC}^{6}$, i.e. $u^{\prime}(A)=v^{\prime}(B)$ :

a. $\quad A=B$ if $u^{\prime}()=.v^{\prime}($.$) . In this case, the equilibrium value of the indemnity is I^{*}=$ $\beta N(e)-b\left(w_{0}, x, y\right)$, which corresponds to full insurance i.e. such as the indemnity covers the full financial loss (the cost of formal care minus the public subsidy). Put

\footnotetext{
${ }^{5}$ The second order condition is satisfied: $V_{I I}=\frac{\delta V^{2}}{\delta^{2} I}<0$.

${ }^{6}$ We do not take into consideration the case where $A>B$ and we suppose that the final wealth of the parent cannot be higher if dependent than if not.
} 
differently, the optimal level of indemnity corresponds to the net cost of the dependency which is covered neither by the child informal care nor by the lump-sum public support. b. $\quad A<B$ if $u^{\prime}()<.v^{\prime}($.$) . In this case, I^{*}<\beta N(e)-b\left(w_{0}, x, y\right)$ which corresponds to partial insurance. Note that Evans and Viscusi (1991) and Finkelstein et al. (2009) showed that the marginal utility of wealth in case of dependency is usually lower than the marginal utility of wealth in case of good health, therefore supporting that optimal LTC insurance purchase is partial.

If the premium is loaded, the FOC implies that $u^{\prime}(A)>v^{\prime}(B)$. Hence, in the case of $u^{\prime}(.) \leq v^{\prime}(),. A<B$ and $I^{*}<\beta N(e)-b\left(w_{0}, x, y\right)$, i.e. partial insurance is optimal. Full insurance is optimal only when $u^{\prime}()>.v^{\prime}($.).

Since we have identified the optimal amount of insurance, we can analyze how this optimal level reacts to a change in informal care. This relationship can be obtained by differentiating the FOC with respect to $I$ and $e$. We have thus:

$$
\operatorname{sgn}\left(\frac{d I^{*}}{d e}\right)=\operatorname{sgn}\left(\frac{\delta^{2} V}{\delta I \delta e}\right)
$$

We have: $V_{I e}=\frac{\delta^{2} V}{\delta I \delta e}=p(1-p)\left(-\beta N^{\prime}(e)\right) u^{\prime \prime}(A)<0$ thus $\frac{d I^{*}}{d e}<0$, which indicates a negative relationship between $I^{*}$ and $e$. This happens as an increase in informal care lowers the purchase of formal care since both are substitutes, which increases final wealth and therefore reduces the demand for insurance.

Concerning the child, the first order condition is expressed as follows:

$$
\bar{V}_{e}=\frac{\delta \bar{V}}{\delta e}=p\left(-s \beta N^{\prime}(e)-\theta\right) \bar{u}^{\prime}\left(A_{C}\right)=0
$$

with $A_{C}=z_{0}+s\left(w_{0}+b\left(w_{0}, x, y\right)-\beta N(e)+(1-\mu) I\right)-\theta e$

The optimal ${ }^{7}$ level of informal care is given by: $-s \beta N^{\prime}\left(e^{*}\right)=\theta$, i.e. such that the marginal cost of effort $(\theta)$ equals the marginal benefit represented by a gain in inheritance due to the parent spending less on formal care in case of dependency $\left(-s \beta N^{\prime}(e)\right)$.

It is worth stressing that the optimal level of effort is nil when the inheritance rate $s$ equals zero. This is in line with our definition of passive altruism under which the decision of the child

\footnotetext{
${ }^{7}$ The second order condition is satisfied: $\bar{V}_{e e}=\frac{\delta \bar{V}^{2}}{\delta^{2} e}<0$.
} 
to provide care to her/his dependent parent is driven only by financial motives, i.e. the possibility to receive an inheritance.

Note also that the optimal level of effort is independent of the level of insurance, i.e. $\bar{V}_{e I}=$ 0 . This means that the optimal level of informal care is not influenced by the level of insurance purchased by the parent. In other words and using Pauly (1990)'s terminology, this means that there is no intra-family moral hazard. It happens because the insurance indemnity is independent of the cost of formal care borne by the child.

The graphical illustration of the joint optimality conditions on $I$ and on $e$ is presented in Fig. 1. We first derive the $I^{*}(e)$ curve, which shows how the optimal $I^{*}$ adjusts to an exogenous change in $e$. The slope of this is negative as previously explained. The other curve $e^{*}(I)$ expresses the optimal level of informal care as a function of a given value of $I$. As previously indicated, in the $(e, I)$ space this curve is vertical, since we know that $e^{*}$ is independent of $I$. The joint optimum is obtained when both curves intersect ${ }^{8}$.

Graphically, the agents' reaction functions and the Nash equilibrium are represented in Fig. 1.

Fig. 1. Reaction functions

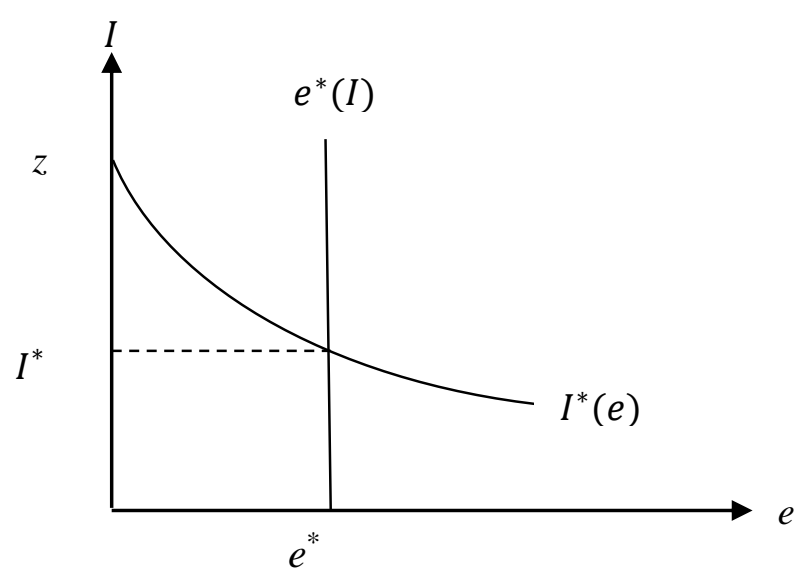

where $z=\beta N(0)-b\left(w_{0}, x, y\right)$ if full insurance and $z<\beta N(0)-b\left(w_{0}, x, y\right)$ if partial insurance.

Two other scenarios now can occur to means-test the level of public support. The first one is to include the level of LTC expenditures to means-test, i.e. to take into account the effective

\footnotetext{
${ }^{8}$ If the level of public support $b$ is independent of wealth, we obtain exactly the same results regarding the relationship between the optimal levels of insurance and informal care.
} 
needs of the dependent individual. The other one is to include the level of insurance benefit in the level of wealth considered to means-test (either in addition or not to LTC expenditures). We will see that this strongly modifies the relationship between insurance and informal care.

\subsubsection{Public support dependent on LTC expenditures}

In this case, the level of wealth to means-test takes into account the level of LTC expenditures. This means that the effective needs (as reflected by LTC expenditures) of the dependent parent is taken into account in the public support. This is what usually happens in France or under the partnership LTC insurance program in some states of the U.S., for which the level of wealth or resources considered to have access to public support depends on effective needs but does not take into account insurance benefits.

The expected utility of the parent is given by:

$W=p u\left(w_{0}-\beta N(e)+I(1-\mu)+b\left(w_{0}-\beta N(e), x, y\right)\right)+(1-p) v\left(w_{0}-\mu I\right)$

The optimal level of insurance $I^{*}$ is given by the first order condition (FOC):

$W_{I}=p(1-\mu) u^{\prime}(\tilde{A})-\mu(1-p) v^{\prime}(B)=0$

with $\tilde{A}=w_{0}+b\left(w_{0}-\beta N(e), x, y\right)-\beta N(e)+(1-\mu) I$

If the premium is actuarially neutral, we still have the same explicit solution as in the previous section, i.e. $I^{*}=\beta N(e)-b\left(w_{0}-\beta N(e), x, y\right)$ if $u^{\prime}()=.v^{\prime}($.$) and I^{*}<\beta N(e)-$ $b\left(w_{0}-\beta N(e), x, y\right)$ if $u^{\prime}()<.v^{\prime}($.

However, the reaction of the optimal insurance to a change in informal care is different from the previous case and given by:

$W_{I e}=p(1-\mu)\left(-\beta N^{\prime}(e)\left(1+b_{w}^{\prime}\right)\right) u^{\prime \prime}$

The sign of $W_{I e}$ depends on the sign of $1+b_{w}^{\prime}$, i.e. how the level of public support varies following a change in wealth. An increase in informal care lowers the purchase of formal care, since both cares are assumed substitutes, which has two effects on final wealth. On one hand, it increases final wealth by an amount of $-\beta N^{\prime}(e)$. On the other hand, since the final wealth is increased, the level of public support is reduced, which lowers final wealth by an amount of $-\beta N^{\prime}(e) b_{w}^{\prime}$. The overall effect depends on the sensitivity of the public support to wealth. If $b_{w}^{\prime}>-1$, the first effect dominates the second and the overall effect of informal care on wealth is positive, which therefore lowers the demand for insurance $\left(W_{I e}<0\right)$. If $b_{w}^{\prime}<-1$, the second 
effect dominates the first, and the overall effect is negative, increasing the demand for insurance $\left(W_{I e}>0\right)$. Finally if $b_{w}^{\prime}=-1$, each effect compensates the other and a change in informal care does not modify wealth and thus has no effect on insurance $\left(W_{I e}=0\right)$. Hence, depending on the value of $b_{w}^{\prime}$, the optimal level of insurance can either react negatively or positively to a change in informal care or be independent of informal care. The parent's reaction curve $I^{*}(e)$ runs as shown in Fig. 2.

The expected utility of the child is given by:

$$
\begin{aligned}
\bar{W} & =p \bar{u}\left(z_{0}+s\left(w_{0}-\beta N(e)+I(1-\mu)+b\left(w_{0}-\beta N(e), x, y\right)\right)-\theta e\right) \\
& +(1-p) \bar{v}\left(z_{0}+s\left(w_{0}-\mu I\right)\right)
\end{aligned}
$$

The FOC with respect to $e$ is:

$$
\bar{W}_{e}=p\left(-s \beta N^{\prime}(e)\left(1+b_{w}^{\prime}\right)-\theta\right) \bar{u}^{\prime}=0
$$

The optimal level of informal care now depends on the value of $b_{w}^{\prime}$ since informal care influences the level of public support through its effect on LTC expenditures. Indeed, if $b_{w}^{\prime}<$ -1 (respectively $b_{w}^{\prime}=-1$ ), then informal care has a negative effect (respectively no effect) on the final wealth of the parent, i.e. on the level of inheritance as discussed previously. In that case, $\bar{W}_{e}<0$, and it is optimal not to provide informal care, i.e. $e^{*}=0$. If $b_{w}^{\prime}>-1$, then informal care has a positive effect on the level of inheritance since $-\beta N^{\prime}(e)$ is superior to $-\beta N^{\prime}(e) b_{w}^{\prime}$. The child has therefore an incentive to provide informal care. The optimal level of which is given by $\theta=-s \beta N^{\prime}\left(e^{*}\right)\left(1+b_{w}^{\prime}\right)$, i.e. such that its opportunity $\operatorname{cost}(\theta)$ equals the gain in inheritance due to the parent spending less on formal care in case of dependency $\left(-s \beta N^{\prime}(e)\left(1+b_{w}^{\prime}\right)\right)$.

As in the previous cases, we have $\bar{W}_{e I}=0$. The child's reaction function is shown in Fig. 2. 
Fig. 2: Reaction functions

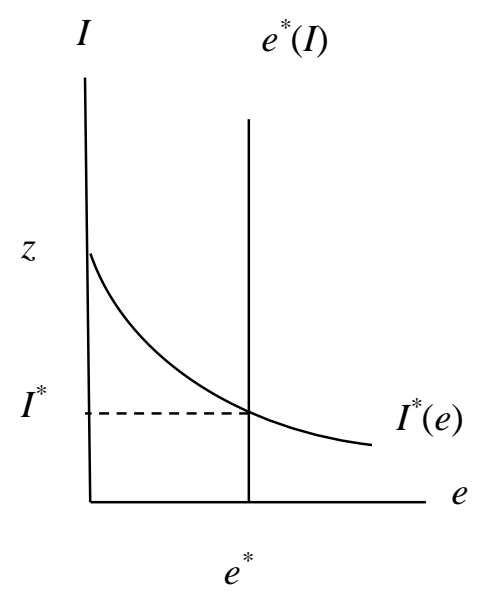

$(A) . b_{w}^{\prime}>-1$

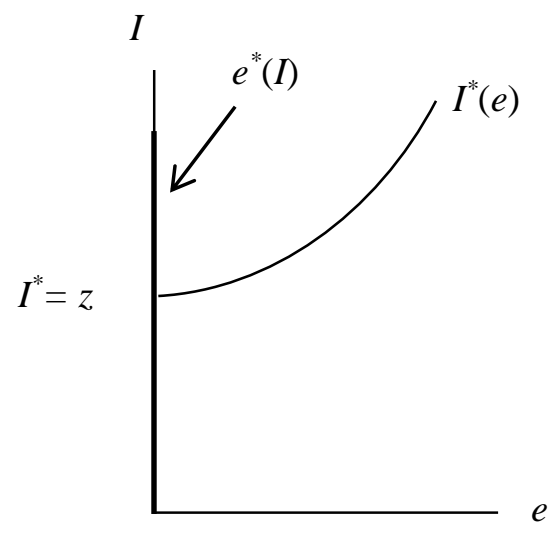

(B). $b_{w}^{\prime}<-1$

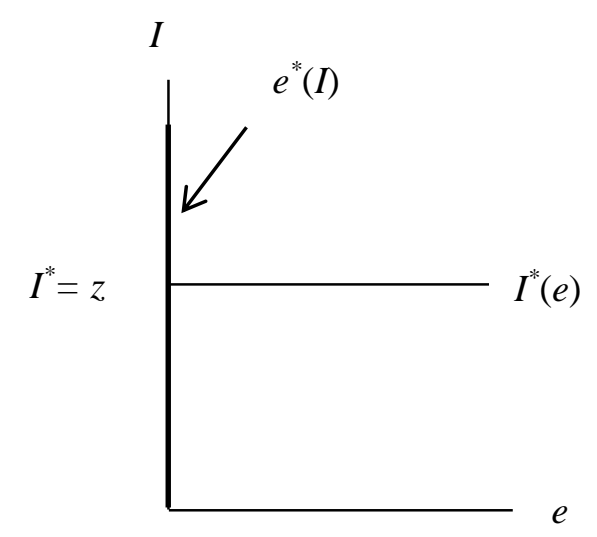

$(C) \cdot b_{w}^{\prime}=-1$

where $z=\beta N(0)-b\left(w_{0}-\beta N(0), x, y\right)$ if full insurance and $z<\beta N(0)-b\left(w_{0}-\right.$ $\beta N(0), x, y)$ if partial insurance.

Hence, when LTC expenditures are included in the level of wealth to be means-tested, the relation between insurance and informal care depends on the sensitivity of the public support with respect to wealth. This is the case because the supply of informal care influences also the level of public support through its effect on LTC expenditures. If public support is stringent, i.e. very sensitive to a change in wealth, the optimal level of insurance reacts positively to a change in informal care, while the optimal level of informal care is nil. If public support is lenient, i.e. weakly sensitive to a change in wealth, the optimal level of insurance reacts negatively to a change in informal care, while the optimal level of informal care is positive. Finally, as can be seen on Fig. 2, at the equilibrium, the optimal level of insurance is lower when public support is lenient. Therefore, there exists a dichotomy in the results depending on the sensitivity of public support to wealth, i.e. a high level of insurance and no informal care for stringent public support, and low level of insurance and positive level of informal care for lenient public support.

In the following section, we consider another possibility to means-test public support.

\subsubsection{Public support dependent on insurance}

Let us now assume that the wealth considered to means-test the level of public support takes into account insurance. This is generally what happens in most public LTC systems which 
consider net wealth at the time of dependency to calculate the level of public support. In such a case, the expected utility of the parents write as ${ }^{9}$

$Y=p u\left(w_{0}-\beta N(e)+I(1-\mu)+b\left(w_{0}-\beta N(e)+I(1-\mu), x, y\right)+(1-p) v\left(w_{0}-\mu I\right)\right.$

The optimal level of insurance is given by:

$$
Y_{I}=p(1-\mu)\left(1+b_{w}^{\prime}\right) u^{\prime}(\overline{\bar{A}})-\mu(1-p) v^{\prime}(B)=0
$$

with $\overline{\bar{A}}=w_{0}+b\left(w_{0}-\beta N(e)+I(1-\mu), x, y\right)-\beta N(e)+(1-\mu) I$

The optimal level of insurance now depends on the value of $b_{w}^{\prime}$. If $1+b_{w}^{\prime} \leq 0$, then $Y_{I}<0$, and it is optimal not to insure i.e. $I^{*}=0$. This happens as the level of public support depends on insurance and in this case the increase in wealth by $I$ is lower than the reduction of public support due to insurance $\left(b_{w}^{\prime} I\right)$. Purchasing insurance therefore lowers wealth in the bad state of nature, and then never improves total wealth.

If $1+b_{w}^{\prime}>0$, purchasing insurance does not lower anymore wealth in the bad state of nature and then $\left.0<I^{*}<\beta N(e)-b\left(w_{0}-\beta N(e)+I(1-\mu), x, y\right)\right)$. Hence, taking into account insurance to means-test tends to decrease the level of insurance purchased compared to the case where insurance is not taken into account to means-test.

Differentiating the FOC with respect to $I$ and $e$, one obtains:

$$
Y_{I e}=p(1-\mu)\left(-\beta N^{\prime}(e)\right)\left[b_{w}^{\prime \prime} u^{\prime}+\left(1+b^{\prime}\right)^{2} u^{\prime \prime}\right]<0
$$

Contrary to the previous situation, the optimal level of insurance is always decreasing in the level of informal care.

The expected utility of the child becomes:

$$
\begin{aligned}
& \quad \bar{Y}=p \bar{u}\left(z_{0}+s\left(w_{0}-\beta N(e)+I(1-\mu)+b\left(w_{0}-\beta N(e)+I(1-\mu), x, y\right)\right)-\theta e\right) \\
& +(1-p) \bar{v}\left(z_{0}+s\left(w_{0}-\mu I\right)\right)
\end{aligned}
$$

The optimal level of informal care is given by the FOC:

$$
\bar{Y}_{e}=p\left(-s \beta N^{\prime}(e)\left(1+b_{w}^{\prime}\right)-\theta\right) \bar{u}^{\prime}=0
$$

\footnotetext{
${ }^{9}$ Note that if LTC expenditures are not considered to means-test, the results are not modified.
} 
which rewrites the same way as in the previous case, i.e. $e^{*}=0$ if $b_{w}^{\prime} \leq-1$ and $\theta=$ $-s \beta N^{\prime}\left(e^{*}\right)\left(1+b_{w}^{\prime}\right)$ if $b_{w}^{\prime}>-1$, but now depends on the level of insurance purchased by the parent since $b$ depends on $I$.

Indeed, differentiating the FOC with respect to $e$ and $I$, one obtains

$$
\bar{Y}_{e I}=-p s \beta N^{\prime}(e)(1-\mu) b_{w}^{\prime \prime} \bar{u}^{\prime}<0
$$

Contrary to the previous case, the optimal level of informal care (whenever positive) is always decreasing with the level of insurance purchased by his elderly parent. This happens as an increase in insurance lowers the level of public support and then modifies the gain in inheritance in case of dependency. To compensate this effect, the child lowers her/his level of informal care. In that case, there exists intra-family moral hazard in the sense that the increase in insurance coverage provides incentives to the child to offer less informal care. Hence considering insurance in the level of wealth to be means-test creates intra-family moral hazard compared to the case where insurance is not included in the level of wealth to be means-tested.

The two reaction functions in the case where $b_{w}^{\prime}>-1$ are represented on Fig. 3 below ${ }^{10}$.

Fig. 3: Reaction functions $\left(b_{w}^{\prime}>-1\right)$

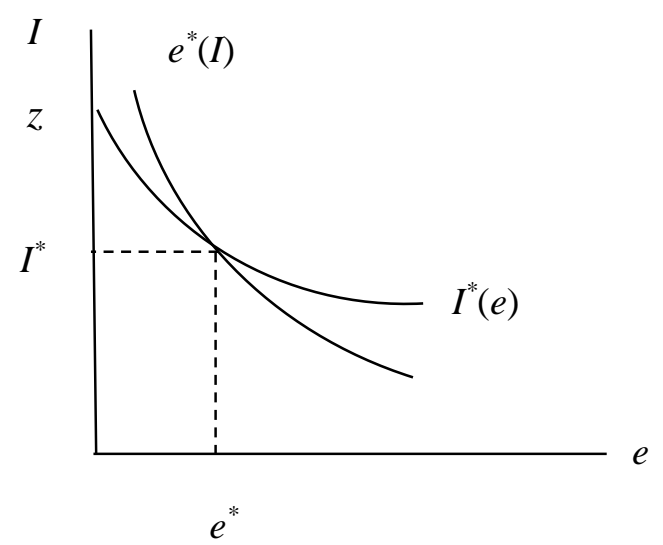

where $\left.z<\beta N(0)-b\left(w_{0}-\beta N(0)+I(1-\mu), x, y\right)\right)$

\subsection{Active altruism}

We now consider the case of active altruism which is defined by the fact that the child also positively values the informal care provided to her/his dependent parent. Following Eeckhoudt

\footnotetext{
${ }^{10}$ Assuming a negative definite Hessian matrix implies that the slope of $e^{*}(I)$ in absolute value is superior to the one of $I^{*}(e)$.
} 
and Courbage (2012), we consider that providing care entails satisfaction to the child via the function $a(e)$ with $a^{\prime}(e)>0$ and $a^{\prime \prime}(e)<0$.

We only consider the expected utility of the child since the expected utility of the parent is not modified by the introduction of active altruism.

\subsubsection{Public support conditioned only by the parent's initial wealth}

In this case, the expected utility of the child becomes:

$\bar{V}=p \bar{u}\left[z_{0}+s\left(w_{0}+b\left(w_{0}, x, y\right)-\beta N(e)+(1-\mu) I\right)-\theta e\right]+p a(e)+(1-p) \bar{v}\left(z_{0}+\right.$ $\left.s\left(w_{0}-\mu I\right)\right)$

The first order condition (FOC) is:

$\bar{V}_{e}=\frac{\delta \bar{V}}{\delta e}=p\left(-s \beta N^{\prime}(e)-\theta\right) \bar{u}^{\prime}\left(A_{C}\right)+p a^{\prime}(e)=0$

The second term of the equation (16) is positive and consequently, the first term has to be negative $\left(-s \beta N^{\prime}(e)<\theta\right)$. Note that in the previous case, i.e. passive altruism, the FOC was $-s \beta N^{\prime}(e)=\theta$ and given that $N^{\prime}(e)<0$ and $N^{\prime \prime}(e)>0$, hence active altruism generates an increase in the optimal level of effort provided by the child ( $e_{\text {active altruim }}^{*}>$ $\left.e_{\text {passive altruism }}^{*}\right)^{11}$. Also, contrary to the case of passive altruism, the optimal level of effort is always positive even if the inheritance rate $s$ equals zero ${ }^{12}$.

By differentiating the FOC with respect to $I$ and $e$, we obtain $\frac{d e^{*}}{d I}=p s(1-$ $\mu)\left(-s \beta N^{\prime}(e)-\theta\right) U^{\prime \prime}\left(A_{C}\right)>0$, which indicates a positive relationship between $e^{*}$ and $I$, contrary to the case of passive altruism under which the optimal effort is independent of insurance. Insurance thus provides incentives to offer informal care pointing to complementarity between insurance and informal care. This happens because insurance covers total expenditure including the cost of informal care which makes it possible to offer more informal care.

The reaction functions of the parent and child are represented in Fig. 4.

\footnotetext{
${ }^{11}$ This can be also proved by evaluating Eq. (16) at the initial level of optimal informal care $\left(\left.\frac{\delta \bar{V}}{\delta e}\right|_{e_{\text {passive altruism }}^{*}}=\right.$ $\left.p a^{\prime}(e)>0\right)$.

${ }^{12}$ When $s=0$, the optimal level of informal care is given by: $a^{\prime}\left(e^{*}\right)=\theta \bar{u}^{\prime}\left(A_{C}\right)$.
} 
Fig. 4. Reaction functions

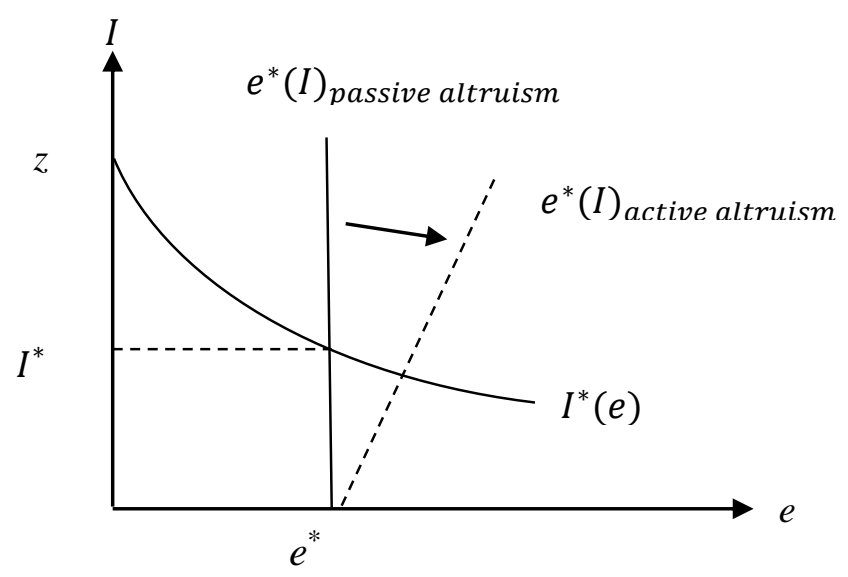

Hence, at the equilibrium, active altruism leads to more informal care and less insurance compared to the case of passive altruism.

\subsubsection{Public support dependent on LTC expenditures}

In this case, the expected utility of the child is given by:

$$
\begin{aligned}
\bar{W} & =p \bar{u}\left(z_{0}+s\left(w_{0}-\beta N(e)+I(1-\mu)+b\left(w_{0}-\beta N(e), x, y\right)\right)-\theta e\right)+p a(e) \\
& +(1-p) \bar{v}\left(z_{0}+s\left(w_{0}-\mu I\right)\right)
\end{aligned}
$$

The FOC with respect to $e$ is:

$\bar{W}_{e}=p\left(-s \beta N^{\prime}(e)\left(1+b_{w}^{\prime}\right)-\theta\right) \bar{u}^{\prime}+p a^{\prime}(e)=0$

As in the previous case, active altruism from the child always induces a positive value of optimal informal care (even if $b_{w}^{\prime} \leq-1$ contrary to the case of passive altruism) which is always superior to the optimal value obtained in the case of a passive altruism $\left(e_{\text {active altruim }}^{*}>\right.$

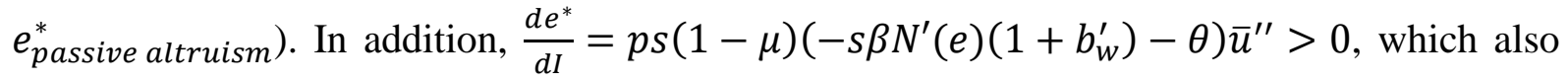
indicates a positive relation bewteen the optimal value of informal care and the level of insurance.

The reaction functions of the two agents are indicated in Fig 5. 
Fig. 5: Reaction functions

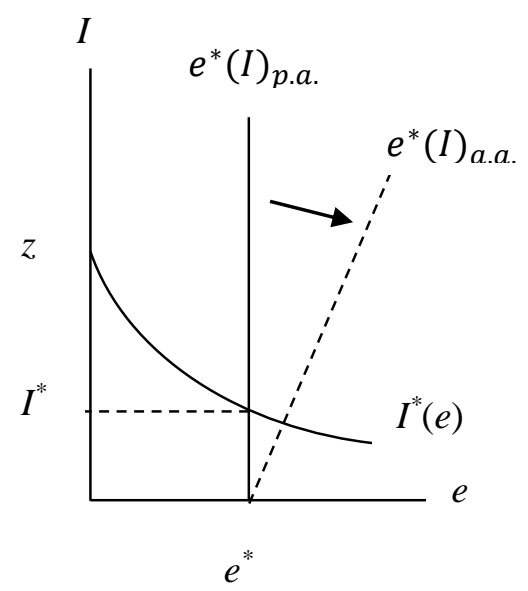

$(A) . b_{w}^{\prime}>-1$

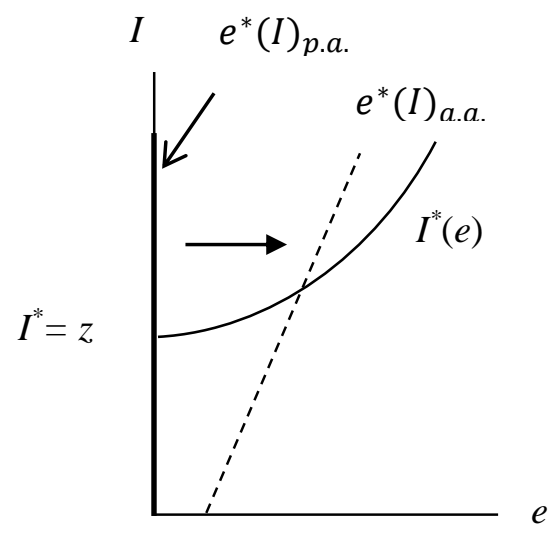

(B). $b_{w}^{\prime}<-1$

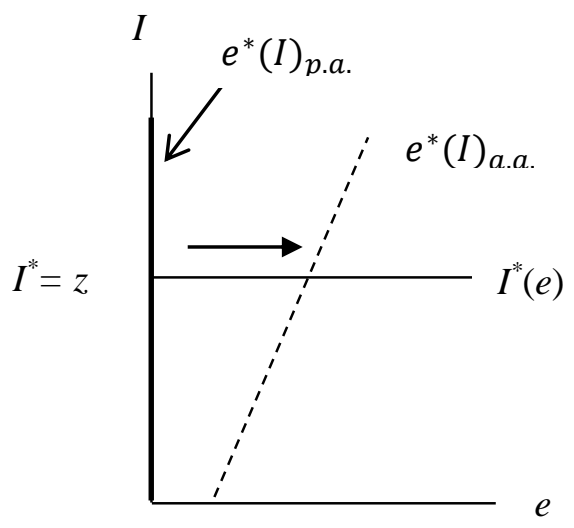

$(C) \cdot b_{w}^{\prime}=-1$

Hence, compared to passive altruism, active altruism leads to more informal care and to either less insurance if public support is lenient or more insurance if public support is stringent.

\subsubsection{Public support dependent on insurance}

The expected utility of the child writes:

$$
\begin{aligned}
& \bar{Y}=p \bar{u}\left(z_{0}+s\left(w_{0}-\beta N(e)+I(1-\mu)+b\left(w_{0}-\beta N(e)+I(1-\mu), x, y\right)\right)-\theta e\right)+ \\
& p a(e)+(1-p) \bar{v}\left(z_{0}+s\left(w_{0}-\mu I\right)\right)
\end{aligned}
$$

The optimal level of informal care is given by the FOC:

$$
\bar{Y}_{e}=p\left(-s \beta N^{\prime}(e)\left(1+b_{w}^{\prime}\right)-\theta\right) \bar{u}^{\prime}+p a^{\prime}(e)=0
$$

which implies that, contrary to the case of passive altruism, $e^{*}>0$ even if $b_{w}^{\prime} \leq-1$. Moreover, $\left(e_{\text {active altruim }}^{*}>e_{\text {passive altruism }}^{*}\right)$ since $\left.\bar{Y}_{e}\right|_{e_{\text {passive altruism }}^{*}}=p a^{\prime}(e)>0$

The reaction of the optimal informal care to a variation of the level of insurance is given by:

$$
\bar{Y}_{e I}=p s(1-\mu)\left\{-\beta N^{\prime}(e) b_{w}^{\prime \prime} \bar{u}^{\prime}+\left(-s \beta N^{\prime}(e)\left(1+b_{w}^{\prime}\right)-\theta\right) \bar{u}^{\prime \prime}\left(1+b_{w}^{\prime}\right)\right\}
$$

If $\left(1+b_{w}^{\prime}\right) \leq 0, \bar{Y}_{e I}<0$ which implies a negative relationship between $e^{*}$ and $I$, contrary to the case of passive altruism for which the optimal effort is nil and independent of $I$. Still contrary to the case of passive altruism, a positive relationship between $e^{*}$ and $I$ can be identified if $\left(1+b_{w}^{\prime}\right)>0$ and $\left(-s \beta N^{\prime}(e)\left(1+b_{w}^{\prime}\right)-\theta\right) \bar{u}^{\prime \prime}\left(1+b_{w}^{\prime}\right)>\beta N^{\prime}(e) b_{w}^{\prime \prime} \bar{u}^{\prime}$.

Graphically, the reaction functions are represented in Fig. 6: 
Fig. 6: Reaction functions

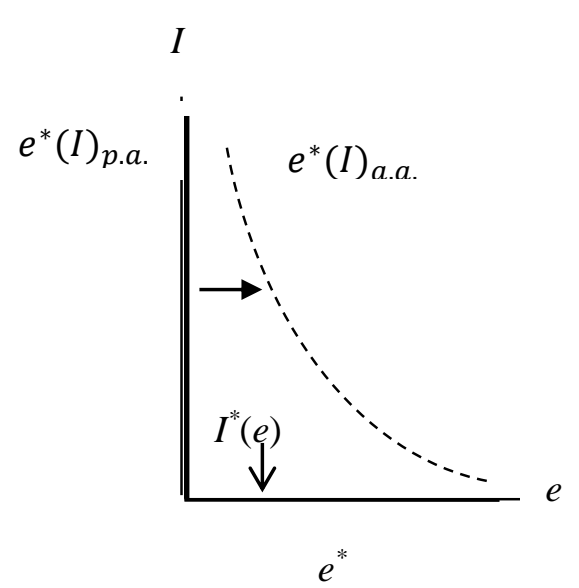

$(A) . b_{w}^{\prime} \leq-1$

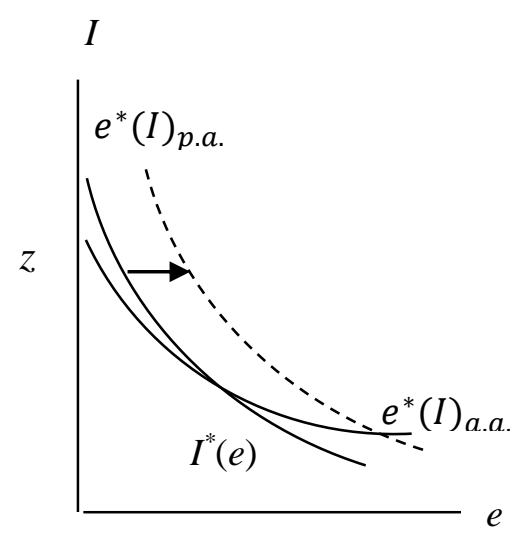

(B). $b_{w}^{\prime}>-1$ and $Q<T$

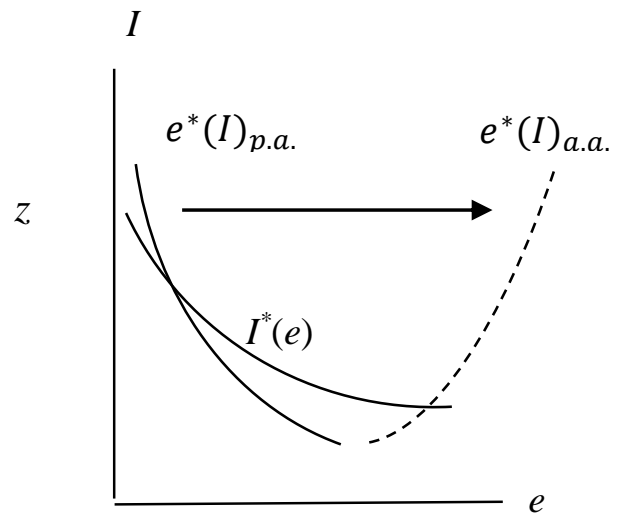

(C). $b_{w}^{\prime}>-1$ and $Q>T$

where $Q=\left(-s \beta N^{\prime}(e)\left(1+b_{w}^{\prime}\right)-\theta\right) \bar{u}^{\prime \prime}\left(1+b_{w}^{\prime}\right)$ and $T=\beta N^{\prime}(e) b_{w}^{\prime \prime} \bar{u}^{\prime}$.

Hence, at the equilibrium, active altruism leads to more informal care and less insurance compared to the case of passive altruism.

\section{Comparative statics}

We analyse the evolution of the joint optimum according to different exogenous shocks. We consider all the exogenous shocks that are likely to have an influence on either insurance or informal care, and thus on the links between these two decisions. These shocks concern the initial levels of wealth of both individuals, the share of the bequest, the cost of formal care, the opportunity cost of informal care, the price of insurance (loading factor), the level of public support, and the stringency of public support.

In order to develop this analysis, we totally differentiate the two first-order conditions with respect to the two endogenous variables and to the exogenous ones. Applying the implicit function rule and Cramer's rule, and assuming a negative definite Hessian matrix, we have $\operatorname{sgn}\left(\frac{d I^{*}}{d \alpha}\right)=\operatorname{sgn}\left(-V_{I \alpha} \bar{V}_{e e}+\bar{V}_{e \alpha} V_{I e}\right)$ and $\operatorname{sgn}\left(\frac{d e^{*}}{d \alpha}\right)=\operatorname{sgn}\left(-V_{I I} \bar{V}_{e \alpha}+\bar{V}_{e I} V_{I \alpha}\right)$ with $\alpha=$ $\left(w_{0}, z_{0}, \theta, s, \beta, \mu, x, y\right)$.

The results are presented below according to the different configurations of public support and details of the computations are provided in Appendixes 1 to 6. 


\subsection{Passive altruism}

Table 1. Comparative statics: Public support dependent on initial wealth

\begin{tabular}{|c|c|c|}
\hline & $I^{*}$ & $e^{*}$ \\
\hline$w_{0}$ & - iif $R_{a}^{u}>R_{a}^{v}$ & 0 \\
\hline$z_{0}$ & 0 & - \\
\hline$\theta$ & + & + \\
\hline$s$ & - & + \\
\hline$\beta$ & + if $X>0$ & 0 \\
\hline$\mu$ & + if $R_{a}^{u}>R_{a}^{v}$ & 0 \\
\hline$x$ & - & 0 \\
\hline$y$ & 0 & \\
\hline
\end{tabular}

with $X=N(e) N^{\prime \prime}(e)-\left(N^{\prime}(e)\right)^{2}$

The first set of results indicates a strict substitutability relationship between insurance and informal care generated by a shock on both the opportunity cost and the inheritance rate. This happens as a rise in opportunity cost, respectively in the inheritance rate, encourages the child to decrease, respectively to increase, the effort provided. These shocks have no direct effect on insurance $\left(V_{I \theta}=0\right.$ and $\left.V_{I S}=0\right)$ and thus, their impact on the insurance level is represented only by the parent's response to the effort provided by the child $\left(V_{I e}<0\right)$.

As for the other shocks, no clear substitutability relationship emerges. This is mainly the case as the impact of these shocks on informal care is nil expect for $\beta$, the price per unity of formal care. In that latter case, a possible complementarity between insurance and informal care could emerge.

Finally, it is worth stressing that impact of the parent's initial wealth $\left(w_{0}\right)$ and the premium per unity of coverage $(\mu)$ on the optimal level of insurance depends on the level of absolute risk aversion and more precisely on a comparison of absolute risk aversion in the state of dependency and the state of good health. There is no common hypothesis on whether risk aversion towards wealth should be higher or lower in the state of dependency or the state of good health. One could argue that risk aversion is lower in the state of good health, as wealth is also higher in this case in a manner analogous to the DARA hypothesis ${ }^{13}$ in the stateindependent situation. Yet, one could also say that the fact of being in a poor state of health

\footnotetext{
${ }^{13}$ As a measure of the risk aversion, the DARA (Decreasing Absolute Risk Aversion) hypothesis indicates that the coefficient of absolute risk aversion decreases with the level of wealth.
} 
could increase risk aversion towards wealth as discussed in the multivariate risk literature (Eeckhoudt, Rey and Schlesinger, 2007).

Table 2. Comparative statics: Public support dependent on LTC expenditures

\begin{tabular}{|c|c|c|c|c|}
\hline & \multicolumn{2}{|c|}{$b_{w}^{\prime}>-1$} & \multicolumn{2}{c|}{$b_{w}^{\prime} \leq-1$} \\
\hline & $I^{*}$ & $e^{*}$ & $I^{*}$ & $e^{*}$ \\
\hline$w_{0}$ & $?$ & - & - iif $R_{a}^{u}>R_{a}^{v}$ & 0 \\
\hline$z_{0}$ & 0 & 0 & 0 & 0 \\
\hline$\theta$ & + & - & 0 & 0 \\
\hline$s$ & - & + & 0 & 0 \\
\hline$\beta$ & $?$ & + & - & 0 \\
\hline$\mu$ & - if $R_{a}^{u} \leq R_{a}^{v}$ & 0 & - if $R_{a}^{u} \leq R_{a}^{v}$ & 0 \\
\hline$x$ & - & 0 & - & 0 \\
\hline$y$ & - & + & 0 & 0 \\
\hline
\end{tabular}

When LTC expenditures are taken into account to means-test the level of public support (table 2), comparative static results in the case of lenient public support $\left(b_{w}^{\prime}>-1\right)$ are very similar to the ones exhibited in the previous case, apart from the effect of $w_{0}$ on insurance and the effect of $y$. For this latter case, a shock on the sensitivity of public support to wealth leads to substitutability between insurance and informal care. In the case of stringent public support, no relationship of substitutability happens as the level of informal care is simply nil.

Table 3. Comparative statics: Public support dependent on insurance

\begin{tabular}{|c|c|c|c|c|}
\hline & \multicolumn{2}{|c|}{$b_{w}^{\prime}>-1$} & \multicolumn{2}{c|}{$b_{w}^{\prime} \leq-1$} \\
\hline & $I^{*}$ & $e^{*}$ & $I^{*}$ & $e^{*}$ \\
\hline$w_{0}$ & $?$ & $?$ & 0 & 0 \\
\hline$z_{0}$ & 0 & 0 & 0 & 0 \\
\hline$\theta$ & + & - & 0 & 0 \\
\hline$s$ & - & + & 0 & 0 \\
\hline$\beta$ & $?$ & $?$ & 0 & 0 \\
\hline$\mu$ & $?$ & $?$ & 0 & 0 \\
\hline$x$ & - & + & 0 & 0 \\
\hline$y$ & $?$ & + & 0 & 0 \\
\hline
\end{tabular}


Finally, when insurance benefits are included in the level of wealth to be means-tested, results are much less clear-cut in the case of lenient public support. This is due to the fact that, contrary to the previous situations, the optimal level of informal care is dependent on the level of insurance $\left(\bar{Y}_{e I}<0\right.$ whereas $\bar{V}_{e I}=0$ and $\left.\bar{W}_{e I}=0\right)$. Indeed, in the case of shocks on $w_{0}, \beta$ and $\mu$, the direct effects on informal care (respectively $\bar{Y}_{e w_{0}}, \bar{Y}_{e \beta}$ and $\bar{Y}_{e \mu}$ ) have to face opposite indirect effects transmitted by the variation of the insurance level, which generates an indeterminate final effect on the optimal level of informal care. Hence, if public support is dependent on insurance benefits as well as lenient, we encounter the largest number of configurations where insurance and informal care could potentially be complementary.

\subsection{Active altruism}

Moving now to the case of active altruism, results are provided respectively in tables 4,5 and 6.

When public support depends only on initial wealth, the main difference with the case of passive altruism is that a positive shock on the child initial wealth impacts negatively insurance and positively informal care (see table 4), while it has no influence in the case of passive altruism (see table 1). This comes from the fact that under active altruism, a higher initial wealth of the child increases her/his marginal satisfaction from providing care (see Eq. (16)) which leads to higher informal care and by substitutability to less insurance.

Table 4. Comparative statics: Public support dependent on initial wealth

\begin{tabular}{|c|c|c|}
\hline & $I^{*}$ & $e^{*}$ \\
\hline$w_{0}$ & $?$ & $?$ \\
\hline$z_{0}$ & - & + \\
\hline$\theta$ & + & + \\
\hline$s$ & - & $?$ if $\bar{V}_{e \beta}<0$ \\
\hline$\beta$ & + if $\bar{V}_{e \beta}<0$ & - if $R_{a}^{u}<R_{a}^{v}$ \\
\hline$\mu$ & $?$ if $R_{a}^{u}<R_{a}^{v}$ & $?$ \\
\hline$x$ & - & 0 \\
\hline$y$ & 0 & \\
\hline
\end{tabular}


When LTC expenditures are taken into account to means-test the level of public support (table 5) and public support is stringent, interestingly, a positive shock on the initial wealth of the child, or a negative shock on the opportunity cost of providing care leads to an increase in both informal care and insurance. Also, the more stringent is public support, the higher both the supply of informal care and the purchase of insurance. It shows that under stringent meanstested public support and when children exhibit active altruism, measures having an effect on the initial wealth of the child, the opportunity cost of informal care or the stringency of public support to wealth can be implemented to increase both insurance and informal care.

Table 5. Comparative statics: Public support dependent on LTC expenditures

\begin{tabular}{|c|c|c|c|c|c|c|}
\hline & \multicolumn{2}{|c|}{$b_{w}^{\prime}>-1$} & \multicolumn{2}{c|}{$b_{w}^{\prime}<-1$} & \multicolumn{2}{c|}{$b_{w}^{\prime}=-1$} \\
\hline & $I^{*}$ & $e^{*}$ & $I^{*}$ & $e^{*}$ & $I^{*}$ & $e^{*}$ \\
\hline$w_{0}$ & $?$ & $?$ & $?$ & $?$ & + & $?$ \\
\hline$z_{0}$ & - & + & + & + & 0 & + \\
\hline$\theta$ & + & - & - & - & 0 & - \\
\hline$s$ & - & + & $?$ & $?$ & 0 & + \\
\hline$\beta$ & $?$ & $?$ & $?$ & $?$ & 0 & + \\
\hline$\mu$ & $?$ & - if $R_{a}^{u} \leq R_{a}^{v}$ & $?$ & - if $R_{a}^{u} \leq R_{a}^{v}$ & $?$ & - if $R_{a}^{u} \leq R_{a}^{v}$ \\
\hline$x$ & - & $?$ & $?$ & $?$ & - & $?$ \\
\hline$y$ & - & + & + & + & 0 & + \\
\hline
\end{tabular}

Finally, when insurance benefits are included in the level of wealth to be means-tested (table 6), the introduction of active altruism makes it possible to sign the effect of many shocks on informal care when public support is stringent.

Table 6. Comparative statics: Public support dependent on insurance

\begin{tabular}{|c|c|c|c|c|c|c|}
\hline & \multicolumn{2}{|c|}{$b_{w}^{\prime}>-1$} & \multicolumn{2}{c|}{$b_{w}^{\prime}<-1$} & \multicolumn{2}{c|}{$b_{w}^{\prime}=-1$} \\
\hline & $I^{*}$ & $e^{*}$ & $I^{*}$ & $e^{*}$ & $I^{*}$ & $e^{*}$ \\
\hline$w_{0}$ & $?$ & $?$ & 0 & - & 0 & - \\
\hline$z_{0}$ & - & + & 0 & + & 0 & + \\
\hline$\theta$ & + & - & 0 & - & 0 & - \\
\hline$s$ & - & + & 0 & $?$ & 0 & + \\
\hline$\beta$ & $?$ & $?$ & 0 & $?$ & 0 & + \\
\hline$\mu$ & $?$ & $?$ & 0 & + & 0 & + \\
\hline$X$ & - & $?$ & 0 & + & 0 & + \\
\hline$y$ & $?$ & $?$ & 0 & + & 0 & + \\
\hline
\end{tabular}




\section{Conclusion}

In the face of increasing LTC needs due to population ageing, LTC financing represents a major societal issue for most developed countries. The financing of LTC expenditures relies on the potential involvement of three specific actors, i.e. public authorities, private insurers and the family. A better understanding on how these sources of financing interact with each other's is thus essential for any decision aiming at sustainable LTC funding. Our paper fills the gap in the literature by exploring theoretically how the structure of means-tested public support influences the nature of the interactions between parents and children and therefore the use of private insurance and of informal care as instruments for LTC financing.

We have considered three scenarios that are possibly encountered in various means-tested LTC schemes. First, the level to be considered for means-testing only takes into account the level of wealth of the recipient without considering the cost of LTC or the possible insurance benefits. Second, the public support considers the LTC needs of the recipient and then integrates the level of LTC expenditures in the level of wealth to means-test public support. Third, the means-test structure includes insurance benefits.

We find that the ways means-tested public support for LTC is structured strongly influence the optimal levels of insurance and informal care as well as their relationship, whether the child exhibits passive or active altruism. Starting with the situation where the child is only interested in the parent's wealth to be bequeathed, we find that when public support depends only on initial wealth, optimal insurance depends negatively on informal care, but the level of informal care is independent of insurance. Yet, when LTC expenditures are included in the level of wealth to be means-tested, then both informal care and insurance depends on the sensitivity of public support to wealth. This happens as the supply of informal care influences also the level of public support through its effect on LTC expenditures. Hence, when public support is stringent, the optimal level of insurance reacts positively to a change in informal care, while the optimal level of informal care is nil. Finally, when insurance is included in the wealth level to means-test, in the case of lenient public support, optimal insurance depends negatively on informal care, and the optimal level of informal care is decreasing with the level of insurance. If public support is stringent, both the optimal levels of insurance and of informal care are nil.

In light of these results, providing incentives to increase informal care, as it occurs in many countries, is likely to lead to an increase in the purchase of insurance only in the case of stringent public support and when LTC expenditures are included in the level of wealth to be means- 
tested. In all other cases, an increase in informal care has either no effect or a negative effect on the purchase of LTC insurance.

We also find that comparative static results may be different from one type of public support to the other. First, whatever the scenario considered, the effect of a shock on the opportunity cost of informal care or on the share of the bequest leads to a change in the opposite direction of insurance and informal care, making insurance and informal gross substitutes. Yet, the effect of other shocks could also potentially lead to complementarity between the two decisions, depending on the way public support is structured.

Our results can also provide some insights on the impact of the recent adoption by several U.S. states of the Partnership LTC Insurance Programme on individual LTC purchase and on informal care. Indeed, under the Partnership programme, the amount of insurance coverage is deducted to qualify for Medicaid coverage, the means-tested U.S. health care programme that provides public support for LTC. Hence, the adoption of the Partnership programme by some states is very similar to moving from a means-test structure that includes insurance (i.e. scenario 3) to a means-test structure that includes only LTC expenditures (i.e. scenario 2). According to our model, the adoption of the partnership programme makes it possible to overcome intrafamily moral hazard which has long been considered as a reason for the sluggish development of private LTC insurance (Pauly 1990; Zweifel and Strüwe 1996, 1998). Also, in the aim of increasing the purchase of LTC insurance, our results suggest that the Partnership programme should be accompanied by incentives to increase informal care and stringent public support.

These results apply to the case where the child is only interested in her/his wealth (and the parent's wealth to be bequeathed) and where child altruism is defined by the fact that she/he derives more utility from wealth if the parent is not dependent than if she/he is. If we assume active altruism, i.e. that the child also derives satisfaction from caregiving, then our conclusions are slightly modified. In particular, we find that when the level of wealth to be means-tested include either only initial wealth or LTC expenditures, then the optimal level of informal care depends positively on insurance. We also find that when LTC expenditures are taken into account to means-test the level of public support and public support is stringent, a higher initial wealth of the child, a lower opportunity cost of providing care, or more stringent public support leads to an increase in both informal care and insurance in the case of stringent public support. This shows that under plausible assumptions, measures having an effect on the initial wealth of the child, the opportunity cost of informal care or the stringency of public support to wealth can be implemented to increase both insurance and informal care. 
Few empirical works address the relationship between informal care and LTC insurance, and results are not homogeneous among themselves. Some empirical evidence appears to indicate substitutability between insurance and informal care. For instance, in the case of Spain, CostaFont (2010) shows that the availability of informal family arrangements is likely to hamper the development of private LTC insurance. Van Houtven et al. (2015), using U.S. data, show that family factors that may indicate future caregiver supply are negatively associated with LTC insurance purchase. Costa-Font and Courbage (2015) using individual expectation data in Europe find evidence consistent with informal care expectations crowding out LTC insurance. However, in contrast to the notion that family members serve as substitutes for LTC insurance, Mellor (2001) shows for the United States that the availability of informal caregivers has no statistically significant effect on LTC insurance purchase. This is confirmed by Courbage and Roudaut (2008), who find for France that the probability of owning LTC insurance increases for those who have a higher probability of receiving informal care should the need arise in the future. An explanation for such complementarity between informal care and LTC insurance could be that in France the level of wealth to mean-test takes into account LTC expenditures and public support is rather stringent. Indeed, according to our results, such configuration of public support leads to complementarity between insurance and informal care. Hence, the theoretical results obtained in this paper could therefore be useful for empirical works studying the relationship between insurance and informal care in stressing the importance of considering the nature of means-tested public support as a relevant variable. By showing that depending on the nature of means-tested public support informal care and LTC insurance could be complementary, the results of this paper therefore question the customary idea that informal care is always a substitute for LTC insurance, and stress the importance of the structure of means-tested public support in driving the interactions between the main sources of LTC funding. 


\section{References}

Brown, J.R., Finkelstein, A. (2009). "The private market for long-term care insurance in the U.S.: A review of the evidence", Journal of Risk and Insurance 76(1), 5-29.

Brown, J., Finkelstein, A. (2008). "The Interaction of Public and Private Insurance: Medicaid and the Long-Term Care Insurance Market", American Economic Review 98(3), 1083-1102.

Chevreul, K., Brigham, K. (2013). "Financing long term care fail elderly in France: The ghost reform", Health Policy 111, 213-220.

Coe, N.B., Van Houtven, C.H. (2009). "Caring for mom and neglecting yourself? The health effects of caring for an elderly parent", Health Economics 18, 991-1010.

Colombo, F., Llena-Nozal, A., Mercier, J., Tjadens, F. (2011), Help wanted?: Providing and paying for long-term care. OECD Health Policy Studies, Paris: OECD.

Costa-Font, J. (2010). "Family ties and the crowding out of long-term care insurance", Oxford Review of Economic Policy 26(4), 691-712.

Costa-Font, J., Courbage, C. (eds.), (2012), Financing long-term care in Europe: institutions, markets and models. Palgrave Macmillan, Basingstoke, U.K.

Courbage, C., Eeckhoudt, L. (2012). “On insuring and caring for parents' long-term care needs", Journal of Health Economics 31, 842-850.

Courbage, C., Roudaut, N. (2008). "Empirical evidence of long-term care insurance purchase in France", The Geneva Papers on Risk and Insurance - Issues and Practice 33(4), 645-656.

Courbage, C., Zweifel, P. (2011). "Two-sided intergenerational moral hazard, long-term care insurance, and nursing home use", Journal of Risk and Uncertainty 43(1), 65-80.

Eeckhoudt, L. Rey, B., Schlesinger, H. (2007). "A good sign for Multivariate Risk taking”, Management Science 53, 117-124.

Laferrère, A., Wolff, F.C., (2006), 'Microeconomic models of family transfers', in S.C. Kolm, J. Mercier Ythier (eds), Handbook on the Economics of Giving, Altruism and Reciprocity, North-Holland, Elsevier, vol. 2, 889-969.

Lafortune, G., Balestat, G. and the Disability Expert Group Members. (2007). "Trends in Severe Disability Among Elderly People: Assessing the Evidence in the 12 OECD Countries and the Future Implications", OECD Health Working Papers 26, Paris OECD.

Mellor, J.M. (2001). "Long-term care and nursing home coverage: are adult children substitutes for insurance policies?”, Journal of Health Economics 20, 527-547.

SCOR (2012), Long-term care insurance, SCOR Global Life, Paris.

Pauly, M. (1990). "The rational nonpurchase of long-term care insurance", Journal of Political Economy 98(1), 153-67.

Pestiau, P., Sato, M. (2008). "Long-term care: the State, the market and the family", Economica $75,435-454$.

Vilaplana Prieto, C., Jiménez-Martín, S. (2015), “Unmet needs in formal care: kindling the 
spark for caregiving behavior", International Journal of Health Economics and Management 15(2), 153-184.

Van Houtven, C.H., Coe, N.B., Konetzka, R.T. (2015). "Family structure and long-term care insurance purchase", Health Economics 24, 58-73.

Van Houtven, C.H., Norton, E.C. (2004). "Informal care and health care use of older adults", Journal of Health Economics 23, 1159-1180.

Van Houtven, C.H., Norton, E.C. (2008). "Informal care and Medicare expenditures: testing for heterogeneous treatment effects", Journal of Health Economics 27, 134-156.

Zweifel, P., Strüwe, W. (1998). "Long-term care insurance in a two-generation model”, Journal of Risk and Insurance 65/1, 13-32.

Zweifel, P., Strüwe, W. (1996). "Long-term care insurance and bequests as instruments for shaping intergenerational relationships", Journal of Risk and Uncertainty 12, 65-76. 


\section{Appendixes}

\section{$\underline{\text { Passive Altruism }}$}

\section{Appendix 1. Public support dependent on initial wealth}

\begin{tabular}{|l|l|}
\hline The parent & The child \\
\hline$\frac{d I}{d w_{0}}<0$ iif $-\frac{u^{\prime \prime}}{u^{\prime}} \leq-\frac{v^{\prime \prime}}{v^{\prime}}\left(R_{a}^{u} \leq R_{a}^{v}\right)$ & $\frac{d e}{d w_{0}}=\frac{d e}{d z_{0}}=\frac{d e}{d x}=\frac{d e}{d y}=\frac{d e}{d \mu}=0$, \\
$\frac{d I}{d z_{0}}=\frac{d I}{d y}=0, \frac{d I}{d \theta}>0, \frac{d I}{d s}<0$ & $\frac{d e}{d \theta}<0, \frac{d e}{d s}>0, \frac{d e}{d \beta}>0$ \\
$\frac{d I}{d \beta}>0$ if $N(e) N^{\prime \prime}(e)-\left(N^{\prime}(e)\right)^{2}>0$ & \\
$\frac{d I}{d \mu}<0$ if $R_{a}^{u}<R_{a}^{v}, \frac{d I}{d x}<0$ & \\
\hline
\end{tabular}

Appendix 2. Public support dependent on LTC expenditures

\begin{tabular}{|l|l|}
\hline The parent & The child \\
\hline$\frac{d I}{d w_{0}} ?, \frac{d I}{d z_{0}}=0, \frac{d I}{d \theta}=-\operatorname{sgn}\left(W_{I e}\right)$ & $\frac{d e}{d w_{0}}<0, \frac{d e}{d z_{0}}=\frac{d e}{d x}=\frac{d e}{d \mu}=0$ \\
$\frac{d I}{d s}<0, \frac{d I}{d \beta} ?, \frac{d I}{d \mu}<0$ if $R_{a}^{u}<R_{a}^{v}$ & $\frac{d e}{d \theta}=\operatorname{sgn}\left(\bar{W}_{e \theta}\right)<0, \frac{d e}{d s}=\operatorname{sgn}\left(\bar{W}_{e s}\right)$ \\
$\frac{d I}{d x}<0, \frac{d I}{d y}=\operatorname{sgn}\left(W_{I e}\right)$ & $\frac{d e}{d \beta} ?, \frac{d e}{d y}=\operatorname{sgn}\left(\bar{W}_{e y}\right)>0$ \\
\hline
\end{tabular}

Appendix 3. Public support dependent on insurance

\begin{tabular}{|l|l|}
\hline The parent & The child \\
\hline$\frac{d I^{*}}{d w_{0}} ?, \frac{d I}{d \beta} ?, \frac{d I}{d \mu} ?, \frac{d I}{d y} ?$ & $\frac{d e^{*}}{d w_{0}} ?, \frac{d e}{d \beta} ?, \frac{d e}{d \mu} ?, \frac{d e}{d z_{0}}=0$ \\
$\frac{d I}{d z_{0}}=0, \frac{d I}{d \theta}>0, \frac{d I}{d s}=-\operatorname{sgn}\left(\bar{Y}_{e s}\right)$ & $\frac{d e}{d \theta}<0, \frac{d e}{d s}=\operatorname{sgn}\left(\bar{Y}_{e s}\right), \frac{d e}{d x}=-\operatorname{sgn}\left(Y_{I x}\right)$ \\
$\frac{d I}{d x}=\operatorname{sgn}\left(Y_{I x}\right)$, & $\frac{d e}{d y}=-Y_{I I} \bar{Y}_{e y}+Y_{I y} \bar{Y}_{e I}>0$, \\
& $\frac{d e}{d y}=p s \beta N^{\prime}(e) b_{w y}^{\prime \prime} \bar{u}^{\prime}\left[p(1-\mu)^{2}(1+\right.$ \\
& $\left.\left.b_{w}^{\prime}\right)^{2} u^{\prime \prime}+\mu^{2}(1-p) v^{\prime \prime}\right]>0$, \\
\hline
\end{tabular}

\section{$\underline{\text { Active altruism }}$}

Appendix 4. Public support dependent on initial wealth 


\begin{tabular}{|l|l|}
\hline The parent & The child \\
\hline$\frac{d I}{d w_{0}}<0$ if $R_{a}^{u}>R_{a}^{v}$ and $b_{w}^{\prime} \geq-1$ & $\frac{d e}{d w_{0}}<0$ if $R_{a}^{u}>R_{a}^{v}$ and $b_{w}^{\prime} \leq-1$ \\
$\frac{d I}{d z_{0}}<0, \frac{d I}{d \theta}>0, \frac{d I}{d s}<0$ & $\frac{d e}{d z_{0}}>0, \frac{d e}{d x} ?, \frac{d e}{d y}=0, \frac{d e}{d \theta}<0, \frac{d e}{d s}>0$ \\
$\frac{d I}{d \beta}>0$ if $\bar{V}_{e \beta}<0 ; \frac{d I}{d \beta} ?$ if $\bar{V}_{e \beta}>0$ & $\frac{d e}{d \beta}>0$ if $\bar{V}_{e \beta}>0 ; \frac{d e}{d \beta} ?$ if $\bar{V}_{e \beta}<0$ \\
$\frac{d I}{d \mu} ?$ if $R_{a}^{u}<R_{a}^{v}, \frac{d I}{d \mu}>0$ if $V_{I \mu}>0$ & $\frac{d e}{d \mu}<0$ if $R_{a}^{u}<R_{a}^{v}, \frac{d e}{d \mu} ?$ if $V_{I \mu}>0$ \\
$\frac{d I}{d x}<0, \frac{d I}{d y}=0$ & \\
\hline
\end{tabular}

\section{Appendix 5. Public support dependent on LTC expenditures}

\begin{tabular}{|l|l|}
\hline The parent & The child \\
\hline$\frac{d I}{d w_{0}} ?, \frac{d I}{d z_{0}}=\operatorname{sgn}\left(W_{I e}\right)$, & $\frac{d e}{d w_{0}} ?, \frac{d e}{d z_{0}}>0, \frac{d e}{d x} ?$ \\
$\frac{d I}{d \theta}=-\operatorname{sgn}\left(W_{I e}\right)$, & $\begin{array}{l}\frac{d e}{d y}=\operatorname{sgn}\left(\bar{W}_{e y}\right)>0, \frac{d e}{d \theta}=\operatorname{sgn}\left(\bar{W}_{e \theta}\right)<0 \\
\frac{d e}{d s}=\operatorname{sgn}\left(\bar{W}_{e s}\right), \\
\frac{d I}{d s}<0 \text { if } b_{w}^{\prime}>-1, \frac{d I}{d s}=0 \text { if } b_{w}^{\prime}=-1 ; \\
\frac{d I}{d s}=\operatorname{sgn}\left(\bar{W}_{e s}\right) \text { if } b_{w}^{\prime}<-1\end{array}$ \\
$\frac{d I}{d \beta} ?, \frac{d I}{d \mu} ?$ & $\frac{d e}{d \mu}<0$ if $b_{w}^{\prime}=-1, \frac{d e}{d \beta} ?$ if $b_{w}^{\prime} \lessgtr-1$ \\
$\frac{d I}{d x}<0$ if $b_{w}^{\prime} \geq-1, \frac{d I}{d x} ?$ if $b_{w}^{\prime}<-1$ & \\
$\frac{d I}{d y}=\operatorname{sgn}\left(W_{I e}\right)$ & \\
\hline
\end{tabular}

\section{Appendix 6. Public support dependent on insurance}

\begin{tabular}{|l|l|}
\hline The parent & The child \\
\hline$\frac{d I^{*}}{d w_{0}} ?, \frac{d I}{d z_{0}}=\operatorname{sgn}\left(Y_{I e}\right)<0$ & $\frac{d e^{*}}{d w_{0}}<0$ if $b_{w}^{\prime} \leq-1, \frac{d e^{*}}{d w_{0}} ?$ if $b_{w}^{\prime}>-1$ \\
$\frac{d I}{d \theta}=-\operatorname{sgn}\left(Y_{I e}\right)>0, \frac{d I}{d s}<0$ & $\frac{d e}{d z_{0}}>0$, \\
$\frac{d I}{d \beta} ?, \frac{d I}{d \mu} ?, \frac{d I}{d x}<0, \frac{d I}{d y} ?$ & $\frac{d e}{d x}>0$ if $b_{w}^{\prime} \leq-1, \frac{d e^{*}}{d x} ?$ if $b_{w}^{\prime}>-1$ and $Q>T$ \\
$\frac{d e}{d y}>0$ if $b_{w}^{\prime} \leq-1, \frac{d e}{d y} ?$ if $b_{w}^{\prime}>-1$ and $Q<T$ \\
$\frac{d e}{d \theta}=\operatorname{sgn}\left(\bar{Y}_{e \theta}\right)<0$, \\
$\frac{d e}{d s}>0$ if $b_{w}^{\prime} \geq-1, \frac{d e}{d s} ? \quad$ if $b_{w}^{\prime}<-1$ \\
$\frac{d e}{d \beta}>0$ if $b_{w}^{\prime}=-1, \frac{d e}{d \beta} ?$ if $b_{w}^{\prime} \lessgtr-1$ \\
$\frac{d e}{d \mu}>0$ if $b_{w}^{\prime} \leq-1, \frac{d e^{*}}{d x} ?$ if $b_{w}^{\prime}>-1$ \\
\hline
\end{tabular}

